\title{
Coronary artery perforation following percutaneous coronary intervention: a case report
}

\author{
Kristina Uglešić*, Ivana Smoljan, Milan Nikšić, Rajko Miškulin, Luka Zaputović \\ University of Rijeka School of Medicine, University Hospital Centre Rijeka, Rijeka, Croatia
}

Introduction: Coronary artery perforation is a severe complication of percutaneous coronary intervention (PCI). It occurs after an intimal tear of the coronary artery that leads to perforation of the arterial wall. A major risk factor for perforation during $\mathrm{PCl}$ is the balloon-to-artery ratio. Ellis classification is used to classify the types of perforation, the type III being the most severe one. Here we report on the case of a patient with the type III perforation after elective $\mathrm{PCl}$.

Case report: A 60-year-old man admitted to our clinic for diagnostic coronary angiography. A significant stenosis of the right coronary artery (RCA) was found. Stent implantation and postdilatation was performed. Postprocedural coronary angiogram showed contrast extravasation, whereas perforation of the RCA was suspected. Urgent pericardiocentesis was performed and blood was aspirated from the pericardium. Patient went into cardiorespiratory arrest and cardiopulmonary resuscitation was started. Sternotomy was carried out by a cardiac surgeon, followed by open heart massage, evacuation of the hematoma and compression of the bleeding site. Return of spontaneous circulation was

\section{Received: $19^{\text {th }}$ Apr 2014}

*Address for correspondence: Klinički bolnički centar Rijeka, Tome Strižića 3, HR51000 Rijeka, Croatia.

Phone: +385-91-5492-495

E-mail: uglesic.kristina@gmail.com established and the patient was taken to the operating room. A complete perforation of the RCA was found. The stent was removed, right ventricle was reconstructed and coronary artery bypass graft with left internal mammary artery to RCA was performed. After the procedure, the patient was admitted to the intensive care unit and transferred back to our clinic after recovery. Two months later he was discharged without any major neurological deficit.

Conclusion: Coronary perforation is a rare complication of $\mathrm{PCl}$, but is associated with significant morbidity and mortality. Type I and type II perforation have a much better prognosis than the type III perforation. It is important to immediately recognize this complication, so the patient could be managed in the best possible way. Treatment strategies for coronary perforation include reversal of anticoagulation, prolonged balloon inflation, implantation of stent grafts, local injection of thrombogenic molecules, placement of microcoils or open heart surgery. In cases where sealing of the perforation by conservative measures cannot be achieved, urgent bypass surgery must be performed.

KEYWORDS: coronary artery perforation, percutaneous coronary intervention, cardiorespiratory arrest, open heart surgery.

CITATION: Cardiol Croat. 2014;9(5-6):181.

\section{Literature}

1. Gunning MG, Williams IL, Jewitt DE, Shah AM, Wainwright RJ, Thomas MR. Coronary artery perforation during percutaneous intervention: incidence and outcome. Heart. 2002;88:495-8.

2. Ellis SG, Ajluni S, Arnold AZ, et al. Increased coronary perforation in the new device era. Incidence, classification, management, and outcome. Circulation. 1994;90(6):2725-30. 3. Störger H, Ruef J. Closure of guide wire-induced coronary artery perforation with a two-component fibrin glue. Catheter Cardiovasc Interv. 2007;70(2):237-40. 